\title{
Potencialidades do Ensino por Investigação para Promoção da Motivação Autônoma na Educação Científica
} (Potentialities of Teaching per Inquiry for Promoting Autonomous Motivation in Science Education)

\section{LUIZ CLEMENT ${ }^{1}$, JOSÉ FRANCISCO CUSTÓDIO² ${ }^{2}$ e JOSÉ DE PINHO ALVES FILHO $^{2}$}

\author{
${ }^{1}$ Universidade do Estado de Santa Catarina (luiz.clement@udesc.br) \\ ${ }^{2}$ Universidade Federal de Santa Catarina (j.custodio@ufsc.br, jopinho@fsc.ufsc.br)
}

\begin{abstract}
Resumo. No ensino de ciências o desinteresse e a baixa qualidade de motivação e engajamento dos estudantes no processo de construção de seus conhecimentos são significativos. Além disso, pesquisas da área ressaltam que há um declínio da motivação para aprender ciências, ao longo do processo de escolarização. Neste artigo, objetivamos evidenciar como a Teoria da Autodeterminação e o Ensino por Investigação podem compor uma abordagem teórica consistente para subsidiar a estruturação e o encaminhamento de ações de ensino-aprendizagem favoráveis à promoção da motivação autônoma de estudantes. Mediante a articulação teórica apresentada, defende-se que ações de ensino por investigação possibilitam ajudas apropriadas para atender tanto os elementos relativos à demanda cognitiva dos estudantes quanto àqueles inerentes à sua dimensão motivacional.
\end{abstract}

Abstract. The disinterest and the low quality of motivation and engagement of students to building their knowledge are evident in science teaching. Moreover, researches in the area point out that there is a decline in student's motivation to learn science, throughout the schooling process. In this paper we have intended to show how the Theory of Self-Determination and the Teaching per Inquiry may constitute a consistent theoretical approach to support the structuring and implementation of teaching actions favorable to the promotion of student's autonomous motivation. Through theoretical articulation presented, it is argued that by teaching per inquiry actions to enable appropriate assistance to support both: elements relating to the cognitive demand of the students and those elements involved in their motivational dimension.

Palavras-chave: teoria da autodeterminação, ensino por investigação, motivação, ensino de ciências Keywords: self-determination theory, teaching per inquiry, motivation, science teaching

\section{Introdução}

No contexto escolar, aspectos relativos à motivação são, em geral, considerados importantes para o envolvimento e o bom desempenho dos alunos, embora muitas vezes seja desconsiderada ou mesmo desconhecida a complexidade em torno dela. De acordo com Bzuneck (2009), a motivação do aluno está atrelada a um contexto específico que é a sala de aula. Em função disso, afirma ele, devem ser considerados os componentes próprios deste meio particular, culturalmente concebido e construído, quando se utiliza os princípios gerais da motivação humana para estudar ou explicar a motivação do aluno. Este fato tem tomado a agenda dos pesquisadores desta temática no campo da educação.

Entre as diferentes teorias adotadas para a análise de relações envolvendo a motivação dos alunos destacam-se, nos estudos mais recentes, a teoria das metas de realização e a teoria da autodeterminação (BORUCHOVITCH, 2007; RUFINI; 
BZUNECK; OLIVEIRA, 2012). Com base nelas foram elaborados e validados instrumentos para avaliar a qualidade motivacional dos alunos, relativos a aspectos gerais da educação ou mesmo direcionados para estudantes do ensino fundamental e do ensino superior. Nas publicações ressalta-se a importância de novos estudos nessa área, tanto para fortalecer os aportes teóricos, bem como para aprimorar os instrumentos utilizados para o mapeamento do construto motivacional no campo da educação (ROTH et. al, 2007; TSAi et. al, 2008; KOH; FRICK, 2010). Destaca-se também a necessidade e importância da realização de investigações focando o ensino médio, bem como, as áreas especificas do saber, uma vez que o construto motivacional poderá variar para diferentes áreas do conhecimento (BORUCHOVITCH; BZUNECK, 2010).

Tomando como exemplo o ensino de Ciências, em geral, e da Física em particular, é significativa a reclamação e denúncia, por parte dos professores, de uma falta de interesse e motivação dos alunos para estudar e aprender Física (RICARDO, 2010). Resultados atuais de pesquisas evidenciam baixa qualidade ou mesmo o declínio da motivação para aprender ciências, ao longo do processo de escolarização de jovens estudantes (BARAM-TSABARI; YARDEN, 2005; KRAPP; PRENZEL, 2011).

Ao mesmo tempo, a legislação educacional brasileira, por meio dos PCN (BRASIL, 2000) defende que o Ensino Médio busque: “[...] a formação geral, em oposição à formação específica; o desenvolvimento de capacidades de pesquisar, buscar informações, analisá-las e selecioná-las; a capacidade de aprender, criar, formular, ao invés do simples exercício de memorização" (p. 5). Diante disso, há uma reorientação nos objetivos do Ensino Médio no sentido de priorizar "[...] a formação ética e o desenvolvimento da autonomia intelectual e do pensamento crítico" (p. 13). Como decorrência destes propósitos deseja-se que os estudantes “[...] desenvolvam competências básicas que lhes permitam desenvolver a capacidade de continuar aprendendo" (p.14).

A defesa de uma formação desta natureza - pautada em uma formação mais autônoma - perpassa também os documentos oficiais elaborados posteriormente aos PCN e DCNEM, como é o caso dos PCN+ (2002) e das Orientações Curriculares Nacionais para o Ensino Médio/OCNs (BRASIL, 2006). Embora exista um discurso favorável à promoção de uma maior autonomia dos estudantes em seu processo de aprendizagem, não há nestes documentos um aprofundamento sobre qual é o entendimento em torno da autonomia prevista. Não há, portanto, clareza conceitual sobre qual é a autonomia buscada tampouco alternativas para operacionalizá-la no 
POTENCIALIDADES DO ENSINO POR INVESTIGAÇÃO PARA PROMOÇÃO DA MOTIVAÇÃO...

contexto de sala de aula. Este aspecto evidencia uma lacuna que demanda de maiores estudos e reflexões para poder ser suprida.

Para a construção de entendimentos sobre a formação autônoma no processo de ensino-aprendizagem, encontra-se na teoria da autodeterminação um suporte teórico importante, como veremos adiante. Mesmo assim, como se trata de contexto educacional, é necessário buscar apoio também em perspectivas didático-pedagógicas. Diante disso, questionamos: como uma perspectiva didático-pedagógica pode dar suporte a ações de ensino-aprendizagem que visam à promoção de regulações mais autônomas - motivação autônoma - de estudantes em contexto escolar?

Vemos no ensino por investigação um aporte teórico-metodológico favorável para a elaboração de ações de ensino-aprendizagem com foco na promoção da motivação autônoma. Portanto, neste artigo, objetivamos evidenciar como a Teoria da Autodeterminação e o Ensino por Investigação podem compor uma abordagem teórica consistente para subsidiar a estruturação e o encaminhamento de ações de ensinoaprendizagem favoráveis à promoção da motivação autônoma de estudantes.

\section{Teoria da Autodeterminação}

$\mathrm{Na}$ teoria da autodeterminação ${ }^{1}$ a leitura e discussão que são feitas em torno da motivação estão baseadas em uma ideia organísmica, centrada fundamentalmente em dois pressupostos. Um pressuposto é o de que os seres humanos são ativos e propensos ao desenvolvimento autorregulável. O outro defende uma dialética pessoa-ambiente, compreendendo o envolvimento dos indivíduos em suas atividades sob o foco de três necessidades psicológicas básicas, inerentes à vida humana: as necessidades de autonomia, de competência e de pertencimento. Assim, a pessoa interage e parte de suas necessidades psicológicas básicas para comprometer-se com o ambiente e este poderá apoiar, frustrar ou ignorar essas necessidades próprias dos seres humanos (DECI et al., 1991; DECI; RYAN, 1985; RYAN; DECI, 2000a, 2000b).

\section{Necessidades Psicológicas}

As necessidades psicológicas (autonomia, competência e pertencimento) estão relacionadas com o self e têm como propósito orientar o desenvolvimento do indivíduo para o crescimento e a adaptação. Evidencia-se uma clara diferença entre elas e as

${ }^{1}$ O termo autodeterminação será utilizado neste artigo para designar motivações autônomas, autorreguladas, com lócus de causalidade interno. 
necessidades fisiológicas (sede, fome, etc), pois, enquanto nas fisiológicas a energia do comportamento é do tipo reativa nas psicológicas ela é proativa (REEVE, 2006; RYAN, 1995; RYAN; DECI, 2000b). As necessidades psicológicas são próprias da natureza dos seres humanos e, portanto, inerentes a todas as pessoas. Por essa razão, elas acabam sendo designadas também como necessidades psicológicas organísmicas (DECI; RYAN, 1990, 2000).

As teorias organísmicas preveem uma dialética pessoa-ambiente, rejeitando e opondo-se à ideia unidirecional ambiente $\rightarrow$ pessoa prevista pelas teorias mecanicistas. Nesta dialética tanto há ação da pessoa sobre o ambiente quanto do ambiente sobre a pessoa, ambos passando por contínuas mudanças (REEVE, 2006; DECI; RYAN, 1990; RYAN; DECI, 2000b). Na abordagem organísmica da motivação assume-se como pressuposto que os seres humanos são ativos e, portanto, organismos com crescimentos orientados e naturalmente inclinados para o estabelecimento de um sistema unificado de interação entre os elementos psíquicos e as estruturas sociais maiores (RYAN; DECI, 2000b).

Para que as pessoas alcancem seu bem-estar psicológico e sintam-se naturalmente motivadas para suas atividades é importante que as necessidades psicológicas organísmicas (autonomia, competência e pertencimento) sejam satisfeitas. Já em situações ou ambientes em que estas necessidades deixam de ser nutridas, prejudica-se a predisposição das pessoas para o seu desenvolvimento saudável (DECI; RYAN, 2000; RYAN, 1995). Esse é também o entendimento de Neves e Boruchovitch (2006) ao afirmarem que o ser humano possui uma tendência motivacional natural, que é responsável pelo seu desenvolvimento cognitivo, social e afetivo.

\section{Autonomia}

O termo autonomia é caracterizado nos dicionários da língua portuguesa como sendo de origem grega (auto-nomia), significando direito ou faculdade de se reger por leis próprias; independência administrativa; faculdade de se governar por si mesmo; emancipação; liberdade moral ou intelectual; independência (FERNANDES; LUFT; MARQUES GUIMARÃES, 1996). Na teoria da autodeterminação a autonomia referese à auto-iniciativa e autorregulação de suas ações (DECI et al., 1991), isto é, nesta teoria "[...] a autonomia é a chave para compreender a qualidade da regulação comportamental" (RYAN; DECI, 2006, p. 1562, tradução nossa). Entende-se então, que uma pessoa atua de forma autônoma quando executa suas tarefas por vontade própria e 
POTENCIALIDADES DO ENSINO POR INVESTIGAÇÃO PARA PROMOÇÃO DA MOTIVAÇÃO...

não por comandos ou por pressões externas, sentindo-se parte da origem e responsável pela própria ação. Na teoria da autodeterminação a autonomia é tida como uma necessidade psicológica básica e, sob este aspecto, se vincula ao e é fundamental para nutrir o " [...] desejo ou a vontade do organismo de organizar a experiência e o próprio comportamento e para integrá-los ao sentido do self" (GUIMARÃES; BORUCHOVITCH, 2004, p. 145).

\section{Competência}

A competência, enquanto necessidade psicológica básica, como é entendida nas abordagens atuais sobre motivação e, particularmente, pela teoria da autodeterminação, fundamenta-se nas conceitualizações apresentadas por White (1959). Em 1959 White publicou um artigo na Psychological Review, intitulado Motivation Reconsidered: The Concept of Competence, que se tornou uma referência fundamental para as abordagens sobre motivação, em especial para o entendimento da competência. Neste trabalho, White propôs o conceito de motivação eficaz/competente (effectance motivation), sob o qual descrevia a existência de uma força inerente ao ser humano, a competência pessoal, que o motivava a interagir de forma eficaz/competente com o seu entorno, o ambiente.

$\mathrm{Na}$ abordagem feita pela teoria da autodeterminação os aspectos sociocontextuais apresentam uma influência direta na percepção de competência, podendo favorecê-la ou prejudicá-la. De um lado a teoria assume que desafios ótimos e feedback positivo/informacional fortalecem, no indivíduo, a percepção de competência para a realização de uma tarefa. Por outro lado, o feedback negativo, pressões externas e situações em que o desafio está acima ou muito abaixo da atual capacidade da pessoa conduzem-na a duvidar de sua competência para a execução da atividade (DECI; RYAN, 2000; RYAN, 1995).

Nesta perspectiva o sentimento de competência poderá auxiliar na geração da motivação intrínseca (maior autodeterminação), mas, não é suficiente para a sua promoção. Conforme é salientado por Deci e Ryan (2000), para que ocorra uma maior motivação intrínseca é necessário que a percepção de competência esteja acompanhada da percepção de autonomia. Portanto, na relação sociocontextual, para além da pessoa se sentir competente para desenvolver a atividade, é necessário que ela perceba a autorregulação de suas ações, isto é, sinta-se responsável pela atuação competente (DECI; RYAN, 2000; GUIMARÃES; BORUCHOVITCH, 2004; RYAN, 1995). 


\section{Pertencimento}

A necessidade de pertencimento abrange as conexões seguras e satisfatórias com os outros em um meio social (DECI; RYAN, 2000). Esta é uma caracterização que expressa o entendimento que se tem, por exemplo, na teoria da autodeterminação sobre a necessidade que o ser humano possui de estabelecer vínculos ou de pertencer, interagir socialmente. A necessidade de pertencimento se configura em um importante constructo motivacional, pois, à medida que as pessoas se sentem apoiadas em suas relações interpessoais, elas apresentam desempenhos melhores, maior resistência a situações promotoras de estresse e alcançam um maior bem-estar psicológico (REEVE, 2006; RYAN; STILLER; LYNCH, 1994).

Guimarães e Boruchovitch (2004, p. 147) ressaltam que "uma ligação entre as necessidades psicológicas básicas de pertencer ou estabelecer vínculos e de autonomia, como determinantes da motivação intrínseca pode, à primeira vista, parecer inconsistente". Porém, estas autoras, apoiando-se nas ideias de Ryan e Stiller (1991), defendem que o indivíduo autônomo não necessita estar desvinculado das demais pessoas, ao contrário, sua autonomia é dependente da sua percepção de ser agente e autodeterminado. Concluem dizendo que "a autonomia tem seu pleno desenvolvimento naquelas situações em que crianças e adolescentes podem se sentir vinculados a adultos significativos" (p. 147).

A satisfação da necessidade de pertencimento facilita a criação de condições e clima favoráveis ao estabelecimento de relações e ao fortalecimento das necessidades psicológicas de autonomia e de competência, produzindo bem-estar e desenvolvimento saudável. Assim, as três necessidades psicológicas básicas, competência, autonomia e pertencimento são integradas e interdependentes (RYAN; DECI, 2000b). Como consequência, motivações com maior grau de autodeterminação podem ser mais facilmente promovidas em ambientes em que as necessidades psicológicas das pessoas são consideradas e supridas.

\section{Motivacão Autônoma}

A teoria de autodeterminação, em conjunto com outras teorias sócio-cognitivas, evidenciaram e descreveram duas formas de motivação, a intrínseca e a extrínseca (DECI et al., 1991; RYAN; DECI, 2000a). A motivação intrínseca se caracteriza pelo interesse e satisfação na atividade em si, isto é, um envolvimento livre, voluntário e sem a necessidade de recompensas ou punições. Já a motivação extrínseca é descritiva de 
POTENCIALIDADES DO ENSINO POR INVESTIGAÇÃO PARA PROMOÇÃO DA MOTIVAÇÃO...

ações e atividades realizadas em resposta a algo externo, visando a obtenção de recompensas, reconhecimento, obediência a ordens ou ainda, para escapar de sanções e punições. Nessa perspectiva, considerava-se que os comportamentos extrinsecamente motivados não possuíam condicionante de autodeterminação, sendo este aspecto válido apenas para comportamentos motivados intrinsecamente. Assim, não se considerava que regulações e valores externos pudessem ser internalizados e se constituir como suportes (condicionantes) para motivações autodeterminadas.

O refinamento teórico, decorrente dos resultados de pesquisas empíricas, conduziu os proponentes da teoria da autodeterminação a considerarem distintos níveis de regulação do comportamento intencional, variando em função do grau de autodeterminação percebida (DECI et al., 1991; DECI; RYAN, 1985). Estes diferentes níveis de regulação acabaram constituindo um continuum da regulação comportamental associada à motivação humana. Foram identificados quatro tipos qualitativamente diferenciados de motivação extrínseca: externa, introjetada, identificada e integrada. A argumentação central para o estabelecimento destes diferentes níveis de regulação comportamental está pautada em torno do conceito de internalização. Por internalização entende-se que há um processo mediante o qual as pessoas transformam regulações por contingências externas em regulações por processos internos (BZUNECK; GUIMARÃES, 2010; DECI et al., 1991). As pesquisas mais recentes evidenciaram com maior clareza e detalhe a existência do continuum da regulação do comportamento (Quadro 1), compreendendo os diferentes tipos da motivação humana, de acordo com o nível de autodeterminação (REEVE, 2006; RYAN; DECI, 2000a, 2000b). 
Quadro 1: Continuum da autodeterminação, tipos de motivação - lócus de causalidade e processos reguladores

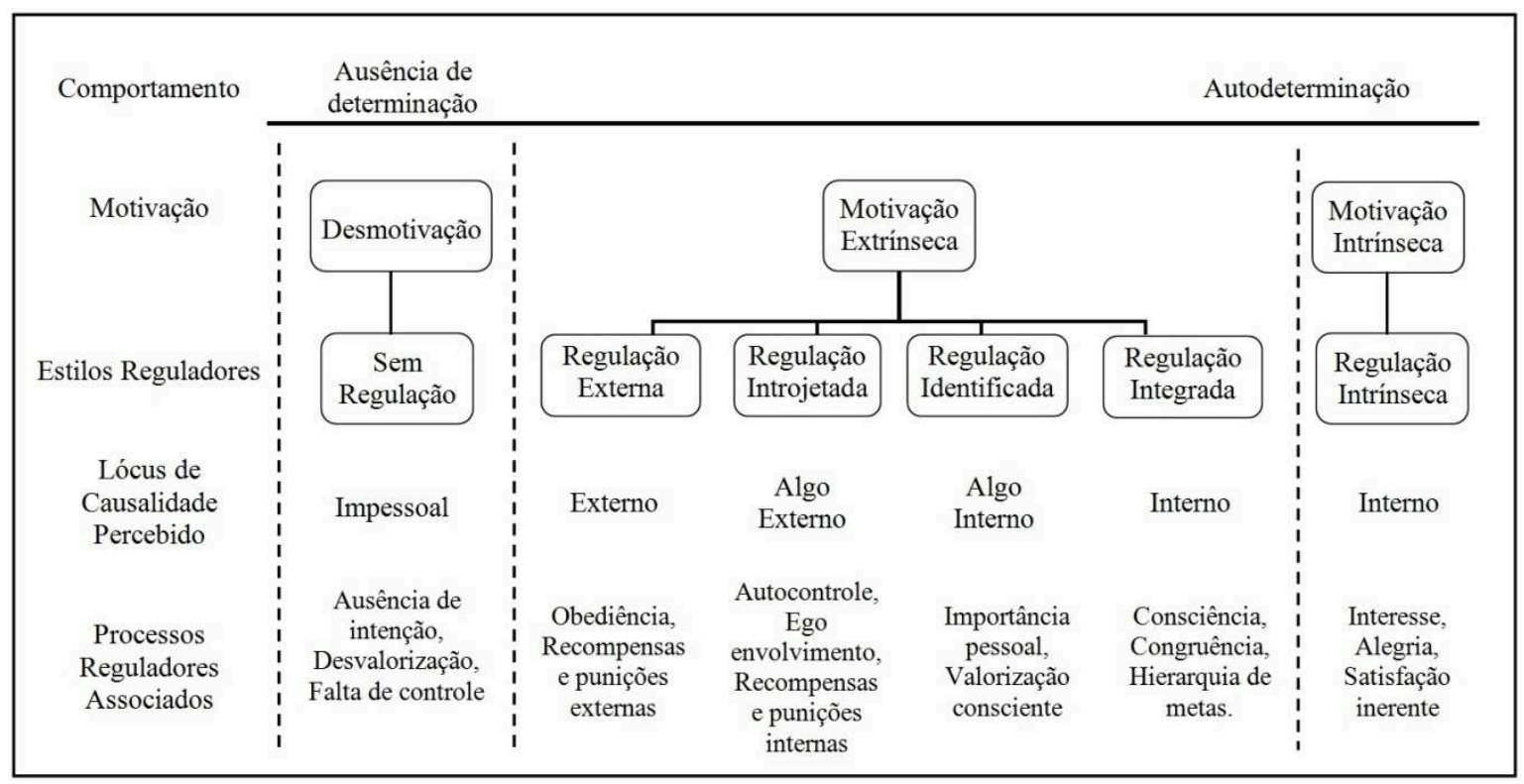

Fonte: Ryan e Deci (2000a, 2000b)

Embora haja na teoria da autodeterminação a proposição de que todo comportamento é intencional, orientado para o alcance de algum objetivo, é possível concluir, mediante análise dos resultados de trabalhos empíricos, que os comportamentos intencionais podem ser autônomos ou controlados (RUFINI; BZUNECK; OLIVEIRA, 2012). De um lado, quando a intenção para agir de uma pessoa não sofre interferência e pressão externa ou intrapsíquica, ela pode ser considerada de iniciativa própria, autônoma. Por exemplo, um estudante faz as atividades escolares porque considera que isso é importante para ele ou lhe gera bem estar (alegria, satisfação, prazer). De outro lado, quando o indivíduo age em função de pressões e cobranças externas ou intrapsíquicas, a sua intencionalidade é do tipo controlada (REEVE, 2006; RYAN; DECI, 2000a). Um exemplo de intenção controlada ocorre quando um estudante decide fazer as atividades escolares para não reprovar, para receber elogios do professor ou para impressionar seus colegas.

No Quadro 1, o lócus de causalidade percebido e os processos reguladores associados permitem identificar quais são as motivações controladas e autônomas. Os dois primeiros tipos de motivação extrínseca (regulação externa e introjetada) são característicos da motivação controlada, enquanto que a motivação extrínseca por regulação identificada e regulação integrada já possuem elevados graus de 
POTENCIALIDADES DO ENSINO POR INVESTIGAÇÃO PARA PROMOÇÃO DA MOTIVAÇÃO...

autodeterminação, isto é, constituem juntamente com a motivação intrínseca níveis motivacionais autônomos.

Em uma análise mais detalhada do continuum da autodeterminação (Quadro 1) constata-se que a desmotivação, localizada na extremidade esquerda, caracteriza-se pela ausência de intenção ou motivação para agir. O primeiro nível da motivação extrínseca é denominado regulação externa. Neste nível motivacional estão compreendidos os comportamentos adotados pelas pessoas em função de controladores externos (nãodeterminados pelo self), por exemplo, o buscar recompensas ou evitar ameaças ou punições. O segundo nível da motivação extrínseca abrange os comportamentos que já assumem certo grau de internalização; em que há uma regulação por introjeção. Na regulação introjetada a pessoa age em função de pressões que ela própria se impõe, por exemplo, cumpre a atividade para evitar sentimentos de culpa, de ansiedade ou mesmo para não afetar sua autoestima. De acordo com Deci et al. (1991, p. 329, tradução nossa) “[...] apesar da regulação introjetada ser interna à pessoa, ela se assemelha muito mais ao controle externo do que com as formas autodeterminadas de regulação, pois envolve a coerção ou a sedução e não implica numa verdadeira escolha". Estes dois primeiros estados da motivação extrínseca são, conforme já havíamos adiantado, comportamentos não-autodeterminados, mas formas controladas de motivação, seja por controladores externos (regulação externa) ou por controladores internos (regulação introjetada).

A regulação identificada, por sua vez, se caracteriza como uma forma mais autônoma de motivação extrínseca. Neste tipo de regulação a pessoa acaba valorizando e se identificando com determinado comportamento de forma a atribuir-lhe uma importância pessoal e, consequentemente, o lócus de causalidade percebido acaba sendo parcialmente interno. O comportamento é tido como de relativa autodeterminação, uma vez que a pessoa age de bom grado, porque os reguladores externos estão alinhados ou são passíveis de indentificação com os valores ou demandas pessoais. Desse modo, a pessoa atua por identificação e não em função de cobranças ou pressões externas. De acordo com Bzuneck e Guimarães (2010), um bom exemplo acaba sendo aquele aluno que tem como propósito tornar-se escritor e, em função disso, valoriza e toma para si as tarefas de fazer leituras. $\mathrm{O}$ aluno percebe que a leitura poderá lhe oferecer importantes contribuições para atingir sua meta pessoal e, portanto, lê motivado por um objetivo pessoal.

O nível mais autodeterminado de motivação extrínseca é a regulação integrada. Neste nível motivacional as regulações são integralmente identificadas e assimiladas ao 
seu self. Ocorrerá, então, uma congruência entre as regulações assimiladas e os valores, necessidades, metas e identidades já anteriormente consolidadas dentro de si. Por exemplo, um aluno é incentivado a realizar leituras e ele as faz com regularidade porque valoriza essa ação, isto é, ler reflete algum valor que ele cultiva. A regulação integrada está muito próxima da motivação intrínseca (alocada no ponto extremo à direita do continuum) já que ambas possuem um lócus de causalidade totalmente interno. No entanto, a motivação intrínseca é caracterizada pelo interesse na atividade em si, sem haver a necessidade de atingir alguma meta, mesmo que seja de importância ou valor pessoal, mediante o desenvolvimento da tarefa. No caso da motivação extrínseca por regulação integrada, mesmo sendo o nível mais autônomo, ainda há dependência com aspectos externos para a regulação.

De acordo com a teoria da autodeterminação o processo de internalização e integração das regulações do comportamento, fortemente intraindividual e espontâneo, com tendência natural de realização pelas pessoas, também apresenta relação com o ambiente (DECI et al., 1991; RUFINI; BZUNECK; OLIVEIRA, 2012; RYAN; DECI, 2000a, 2000b). Assim sendo, o contexto social em que as atividades são desenvolvidas pelas pessoas poderá favorecer ou dificultar esse processo. Há, portanto uma previsão teórica de que comportamentos iniciados por eventos externos possam ser internalizados e integrados pelas pessoas, atribuindo um valor inerente à tarefa e, consequentemente, nutrindo e maximizando a motivação intrínseca para sua execução.

Com base nesse entendimento sobre a influência dos fatores sócio-ambientais no processo de internalização e integração de reguladores comportamentais e na caracterização e tipificação da motivação humana, têm-se na teoria da autodeterminação um referencial teórico valioso para os estudos relativos à motivação escolar. Cabe, no entanto, avaliar quais perspectivas didático-pedagógicas poderão subsidiar ações de ensino-aprendizagem que oferecerão suportes à promoção da motivação autônoma dos estudantes.

\section{Ensino por Investigação}

A origem do ensino por investigação (inquiry) é norte americana. Seu propósito inicial era oferecer uma forma de ensino que pudesse se opor ao modelo diretivo. No ensino diretivo se assumia que a Ciência era constituída, essencialmente, de um corpo de conhecimentos que devesse ser aprendido pelos estudantes mediante instruções 
POTENCIALIDADES DO ENSINO POR INVESTIGAÇÃO PARA PROMOÇÃO DA MOTIVAÇÃO...

diretivas, do professor para o estudante (NATIONAL RESEARCH COUNCIL - NRC, 2008).

Segundo Barrow (2006), foi John Dewey o primeiro a manifestar críticas ao modelo diretivo de ensino, afirmando que o ensino de ciências dá muita atenção à acumulação de informações e deixa de lado o aspecto dela como forma de pensar. No início do século XX, Dewey defendia que a Ciência é mais que um corpo de conhecimento a ser aprendido; é, também, um processo ou método para aprender. O contexto norte americano, no início do século XX era propício para a busca de novas orientações e transformações, pois, em meio a crise econômica implantada com a queda da bolsa de Nova Iorque, em 1929, várias medidas governamentais tiveram que ser adotadas para minimizar o desemprego e a falência do sistema fabril. Dewey, como representante do movimento progressista, propunha e discutia uma educação escolar que contribuísse com a construção de uma sociedade mais humanizada, guiada por projetos democráticos (ANDRADE, 2011; BARROW, 2006).

A partir da ideia de que a Ciência pudesse orientar e estruturar uma forma de se ensinar e aprender, Dewey propôs um modelo que serviu de base para a elaboração de uma proposta para o ensino de ciências na educação secundária dos EUA (Science in Secondary Education), coordenada pela Comissão Curricular da Educação Secundária de 1937. Em meados da década de 40, Dewey reviu sua interpretação sobre o método científico e acabou modificando seu modelo de ensino. Essa mudança visava atender de forma mais apropriada o desenvolvimento do pensamento reflexivo dos estudantes. Esse último modelo sugeria que os problemas a serem estudados deveriam estar relacionados com as experiências dos estudantes, bem como, com a sua capacidade intelectual e, acima de tudo, os estudantes deveriam ser ativos em sua busca pelas soluções (BARROW, 2006).

De acordo com o NRC (2008), durante as décadas de 50 e 60, o ensino por investigação foi se fortalecendo e tornou-se uma perspectiva de ensino-aprendizagem importante para o ensino de ciências. Para isso a influência do educador Joseph Schwad acabou sendo determinante. Para Schwad “[...] os professores devem apresentar a ciência como investigação e os alunos devem usar a investigação para aprender assuntos de ciência" (NRC, 2008, p. 15, tradução nossa). Conforme DeBoer (2006), esta visão em relação ao ensino de ciências, fortalecida pelas práticas experimentais e orientadas por uma abordagem investigava, tinha até meados do século XX, uma preocupação essencialmente voltada à formação intelectual individual dos estudantes. 
A partir da década de 1950, a visão do ensino de ciências nos EUA acaba modificando seu foco. Passou a prevalecer a ideia central da investigação como elemento fundamental para orientar o ensino e a aprendizagem, tendo como objetivo maior, porém, a preparação de indivíduos que pudessem se tornar cientistas e formar um público que valorizasse e fosse simpático à Ciência. Com isso, os EUA visavam estabelecer e manter um programa educacional forte em ciência, de forma a manter e garantir a segurança do país (DEBOER, 2006). Esta visão perdurou por cerca de duas a três décadas.

Há um momento histórico mundial significativo que motivou ainda mais os EUA a modificarem o foco do ensino de ciências no país, qual seja: o lançamento do Sputnik I pelos russos, em 4 de outubro de 1957 (BARROW, 2006). O projeto de Física do Physical Science Study Committee, atualmente mais conhecido pela sigla PSSC (iniciado em 1957) figura como o maior representante do movimento renovador e inovador no ensino de ciências nos EUA (PINHO-ALVES, 2000). Nos anos posteriores também foram desenvolvidos projetos e materiais curriculares para outras áreas do conhecimento, por exemplo: Biologia (Biology Science Curriculum Study - BSCS) e para a Química (Chemical Education Materials Study - Chem Study). Todos estes projetos focavam em um ensino baseado fortemente na prática experimental, procurando levar os alunos a vivenciar algumas etapas fundamentais da atividade científica (observação, classificação, inferência, controle de variáveis, coleta e interpretação dos dados, conclusão). O objetivo era levar o estudante a pensar como cientista (ANDRADE, 2011; BARROW, 2006; DEBOER, 2006).

Conforme destacado por Andrade (2011), durante este mesmo período - nas décadas de 1950 e 1960 - também se conduzia uma reforma curricular em nosso país, visando a preparação "[...] dos jovens para suprir a demanda de pesquisadores que impulsionariam o desenvolvimento científico e o consequente progresso do país" (p. 124). Estas reformas estavam sendo encabeçadas pelo Instituto Brasileiro de Educação, Ciência e Cultura - IBECC. Dentre as atividades desenvolvidas pelo IBECC estava o trabalho de tradução dos projetos estrangeiros, como foi o caso do PSSC. Apoiado no PSSC tinha-se como propósito valorizar as práticas experimentais e trazer o foco da investigação cientifica para o ensino de ciências no Brasil.

Assim como no Brasil, os projetos de ensino de ciências norte-americanos foram traduzidos e utilizados nos sistemas educacionais de diversos países. No NRC (2008) afirmava-se que o movimento de mudança ocorrido no ensino de ciências durante as 
décadas de 1950, 1960 e 1970 contribuíram "[...] amplamente para a disseminação da ideia de ajudar os alunos a desenvolver habilidades investigativas e de compreeder a ciência como um processo de investigação" (p. 17, tradução nossa). No entanto, há de se ressaltar que a perspectiva investigativa presente neste período carregava uma visão de Ciência neutra e desenvolvida sob "o" método científico. Este aspecto fez com que o ensino de ciências baseado nessa perspectiva investigativa fosse questionado e criticado, pois, segundo os críticos, sua visão de ensino não proporcionaria uma formação que habilitasse os estudantes para as diferentes situações que teriam que enfrentar na vida, bem como, apresentava inconsistências epistemológicas sobre a Ciência (CHINN; MALHOTRA, 2002; DEBOER, 2006).

No final da década de 1980 e início da década de 1990 ocorreu uma segunda reforma curricular nos EUA, guiada por documentos oficiais nos quais a investigação como prática para o ensino de ciências assumiu novo significado. Segundo DeBoer (2006), a educação em ciências assumiu uma denominação mais ampla, intitulada de Alfabetização Científica, que "[...] incluía uma compreensão do conteúdo da ciência pelo seu valor cultural, disciplinar e intelectual e para sua aplicação no dia-a-dia para auxiliar na tomada de decisão e resolução de problemas" (p. 32, tradução nossa). Constata-se aqui uma argumentação que, de forma implícita, defende uma formação da autonomia dos estudantes. Fazemos esta ressalva, pois o discurso sobre o ensino por investigação ora retratado destaca que esta perspectiva de ensino tem como papel proporcionar o desenvolvimento de capacidades dos estudantes para resolver problemas pessoalmente e socialmente relevantes, para o desenvolvimento intelectual pessoal e ainda como um dispositivo motivacional (BARROW, 2006; DEBOER, 2006).

A partir de então, na legislação educacional norte-americana, por exemplo, no National Science Education Standards - NSES (National Research Council, 1996), a investigação aparece como foco central da alfabetização científica. Foi elaborado em 2000 um volume específico (Inquiry and the National Science Education Standards: a guide for teaching and learning) de acompanhamento para detalhar e orientar os professores sobre o ensino por investigação (BARROW, 2006; DEBOER, 2006).

No NSES (NATIONAL RESEARCH COUNCIL, 1996, p. 23, tradução nossa) afirma-se que:

[...] Investigação científica refere-se às diversas maneiras em que os cientistas estudam o mundo natural e propõem explicações baseadas na evidência derivada de seu trabalho. Investigação também se refere às atividades de estudantes em que eles desenvolvem conhecimento e 
compreensão das ideias científicas, bem como, uma compreensão de como os cientistas estudam o mundo natural.

Nesta citação fica evidenciado que já não há mais uma compreensão de ciência neutra e desenvolvida por um único método, mas sim, uma ciência desenvolvida pelo trabalho humano. É visível a defesa de que o ensino de ciências pode ser guiado por uma perspectiva investigativa, na qual os estudantes poderão se apropriar dos conhecimentos científicos e compreender como se produz ciência, ou seja, ao mesmo tempo em que aprendem ciências também podem aprender sobre ciências. Portanto, com as reformas curriculares dos anos 1980 e 1990, a noção de investigação com o propósito de orientar o ensino e a aprendizagem de ciências assumiu novas perspectivas.

De acordo com DeBoer (2006), uma das justificativas principais para o uso do ensino por investigação manifestado nas publicações do NRC está pautada na argumentação de que o ensino por investigação é uma das mais eficazes estratégias de ensino. Em razão de ser mais envolvente, consequentemente, os estudantes aprenderiam mais em abordagens baseadas na investigação. A constatação de DeBoer se sustenta em algumas afirmações feitas, por exemplo, no Inquiry and the National Science Education Standards (NRC, 2008). Em uma parte deste documento, em que se defende que entender ciência é mais do que conhecer fatos, os autores trazem resultados de pesquisas em educação em que o foco estava voltado a entender o que auxilia estudantes a utilizar e aplicar conhecimentos em situações novas, e um dos aspectos ressaltados é que "[...] a disposição de procedimentos investigativos ajudam as pessoas a resolver novos problemas de maneira eficiente e eficaz" (p. 116, tradução nossa). Além disso, se ressalta no documento que o ensino por investigação fomenta os estudantes a

[...] desenvolver suas habilidades para questionar, raciocinar e pensar criticamente sobre fenômenos científicos, tomando um controle cada vez maior sobre sua própria aprendizagem. Eles podem usar seus maiores conhecimentos de ciência e as habilidades investigativas para abordar outras questões e problemas e para desenvolver ou testar explicações para outros fenômenos de seu interesse. (p. 120, tradução nossa).

Com isso, percebe-se que os documentos da NRC concebem o ensino por investigação como uma abordagem pedagógica que é consistente com a natureza da ciência e que fornece a formação de conhecimentos e habilidades úteis para a abordagem de problemas de interesse pessoal ou social (DEBOER, 2006). 
POTENCIALIDADES DO ENSINO POR INVESTIGAÇÃO PARA PROMOÇÃO DA MOTIVAÇÃO...

No entanto, em função da longa e variada história do ensino por investigação para a educação em ciências, persistem diferentes compreensões em torno desta perspectiva de ensino-aprendizagem. Este aspecto ficou evidenciado no artigo de Abd-el-khalick et al. (2004), em que é retratada uma análise feita a partir de relatos de experiências apresentados em um Simpósio Internacional, no qual estavam reunidos pesquisadores de diferentes países, com realidades educacionais distintas, mas que objetivavam a promoção do ensino de ciências baseado na investigação. Os distintos entendimentos em torno do ensino por investigação estavam atrelados as suas referências, isto é, ou estavam focados na ideia anterior à década de 1950, ou na visão estabelecida após a primeira reformulação curricular nos EUA (1950 até final de 1970), ou ainda, já traziam a compreensão atual, após a segunda reformulação curricular norte-americana (nas décadas de 1980 e 1990).

A visão mais recente em torno do ensino por investigação orientou vários e importantes estudos realizados na Espanha (BALLENILLA, 1999; CAÑAL et al., 1997; FLOR, 1996; GARCÍA; GARCÍA, 2000; entre outros). Estes trabalhos, apoiados em uma perspectiva construtivista, apresentam reflexões tanto teóricas (o ensino por investigação como alternativa para estruturar um currículo - como modelo didático; como uma metodologia, orientando uma determinada sequência de atividades didáticas) quanto sobre descrições apoiadas em análises de práticas educativas desenvolvidas sob uma perspectiva de ensino por investigação.

Para García e García (2000), a investigação é uma possibilidade frutífera no processo de formulação e tratamento de problemas, pois ela se refere a "uma estratégia de conhecimento e atuação na realidade própria do comportamento de nossa espécie, comum à população humana e com um claro valor adaptativo para o indivíduo" (Tradução nossa; p. 11). Eles continuam afirmando que a investigação, desde a perspectiva de resolução de problemas, "estaria presente tanto na atividade científica como na prática cotidiana, variando, em cada caso, o tipo de problemas levantados e os procedimentos utilizados em sua resolução" (Tradução nossa; p. 12).

No ensino por investigação, visando a promoção da aprendizagem, assume-se que as diferentes estratégias de ensino que poderão ser adotadas devem considerar que é fundamental ter a definição de um problema (ou uma situação-problema). Azevedo (2009, p. 19) afirma que "Se tivermos como objetivo um planejamento e uma proposta de ensino por investigação, não podemos utilizar o título problema inadequadamente". A autora sinaliza para uma distinção entre o que se pode considerar como um problema 
propriamente dito e o que se apresenta como um simples exercício. De maneira bastante genérica, pode-se afirmar que uma dada situação caracteriza-se como um problema para um indivíduo quando, ao procurar resolvê-la, ele não chega a uma solução de forma imediata ou automática. Neste caso, necessariamente, o solucionador envolve-se num processo de reflexão e de tomada de decisões para chegar a uma solução. Numa atividade envolvendo apenas exercícios, por sua vez, o que se observa é o uso de rotinas/passos automatizados, quer dizer, as situações com as quais o indivíduo se depara já são por ele conhecidas, podendo ser resolvidas por meios ou caminhos habituais (CLEMENT, 2004; GARCÍA; GARCÍA, 2000).

A distinção entre problema e exercício, porém, é bastante sutil, não podendo ser especificada em termos absolutos (PEDUZZI, 1997). Para uma determinada pessoa uma situação proposta pode configurar-se em um problema, enquanto que para outra ou até para esta própria pessoa em um momento posterior, a mesma situação pode ser vista como um mero exercício. Por isso esta distinção, em última instância, dependerá de cada indivíduo (de seus conhecimentos, de sua experiência e do grupo cultural de que faz parte), da tarefa proposta e de sua atitude diante dela.

Tendo em vista o papel do problema em processos de construção de conhecimento, seja ele científico ou escolar, a argumentação presente na literatura em torno do ensino por investigação dele é bastante favorável. Sinaliza-se, por exemplo, que esta forma de ensino estimula os alunos a refletir, debater, formular questionamentos, elaborar e confirmar ou refutar hipóteses, justificar ideias e aplicar conhecimentos em situações novas (AZEVEDO, 2009; GIL PÉREZ et al., 1992; MUNFORD; LIMA, 2007; SEGURA; MOLINA; PEDREROS, 1997).

Menciona-se ainda que o ensino por investigação, dentre outros objetivos, vislumbra uma proposta de ensino-aprendizagem que aproxime as ações didáticas ao fazer científico, ou seja, oportuniza ao aluno aprender ciência e sobre ciência (DEBOER, 2006; GARCÍA; GARCÍA, 2000; NRC, 2008). Com base nesse conjunto de argumentos, os trabalhos na área de educação científica buscaram apresentar propostas de como elaborar e desenvolver atividades didáticas com caráter investigativo.

Assim, há por um lado perspectivas educacionais mais abrangentes e que buscam uma reestruturação curricular em torno da investigação (CAÑAL, 1997; CARVALHO, 2013) e outras mais pontuais, focadas na reorientação de atividades didáticas específicas e pautadas em diferentes recursos (CARVALHO, 2010; BORGES, 2002; CLEMENT, 2004; CLEMENT; TERRAZZAN, 2012; FLOR, 1996; GARCÍA; GARCÍA, 2000; GIL 
PÉREZ et al., 1992; MENEGAT; CLEMENT; TERRAZZAN, 2007; SEGURA; MOLINA; PEDREROS, 1997).

De acordo com a literatura da área, a dinâmica de atividades didáticas por investigação pode desenvolver-se de diferentes formas: por meio de uma atividade de lápis e papel (resolução de problemas abertos); de uma atividade com uso de experimento (com diferentes níveis de abertura); de uma atividade com uso de texto; ou ainda, por sequências de ensino investigativas. Além disso, outros tipos de atividades investigativas são possíveis, tais como: atividades teóricas, em que os alunos se envolvem em estudos de caso e deverão se posicionar frente a assuntos controversos; atividades com banco de dados, tendo como desafio a elaboração de uma argumentação baseada em evidências; atividades de simulação, explorando um fenômeno a partir de simulações em computador (SÁ et al., 2007). Entretanto, qualquer que seja o recurso metodológico predominante ou o encaminhamento dado, há sempre a presença de uma situação-problema em torno da qual a atividade se desenvolve e a investigação se concretiza.

\section{Articulação Teórica: Suporte para Promover a Motivação Autônoma}

Podemos questionar: o ensino por investigação é uma alternativa didáticopedagógica promissora para objetivos educacionais que vão para além das aprendizagens de ciências e sobre ciências, provendo também a motivação autônoma dos estudantes? Acreditamos que há uma relação entre o ensino por investigação e a teoria da autodeterminação aplicada ao contexto escolar. A teoria da autodeterminação prevê que os seres humanos possuem algumas necessidades psicológicas, como a competência, a autonomia e o pertencimento; quando satisfeitas, sua motivação intrínseca é maior e, consequentemente, seus esforços são mais eficazes e significativos.

O ensino por investigação prevê, dentre outros aspectos, uma participação ativa do estudante no processo de ensino-aprendizagem, o que lhes atribui maior controle sobre a sua própria aprendizagem. Os estudantes podem participar da discussão para problematização e apropriação das situações-problemas; fazer perguntas de forma a debater aspectos que sejam de seu interesse e que estejam relacionados às situaçõesproblema; interagir com os seus colegas ao longo do trabalho; elaborar hipóteses, estratégias e propor soluções; relatar, discutir e avaliar os resultados alcançados. Com isso eles terão a possibilidade de desenvolver maior senso de controle e autonomia diante do desenvolvimento das atividades. A necessidade de relacionamento também 
pode ser satisfeita pelas interações estabelecidas com os colegas nos trabalhos em grupo e com o professor, durante as orientações e ajudas buscadas junto a ele. Afora isso, todo processo de apropriação conceitual, procedimental e atitudinal contribuirá de forma significativa para o desenvolvimento da competência dos estudantes.

No esquema mostrado na Figura 1, sintetizamos nosso entendimento sobre como o ensino por investigação poderá auxiliar no desenvolvimento das regulações motivacionais dos estudantes em prol da promoção de sua autodeterminação:

Figura 1: Diagrama das características essenciais do Ensino por Investigação em busca da Motivação Autônoma.

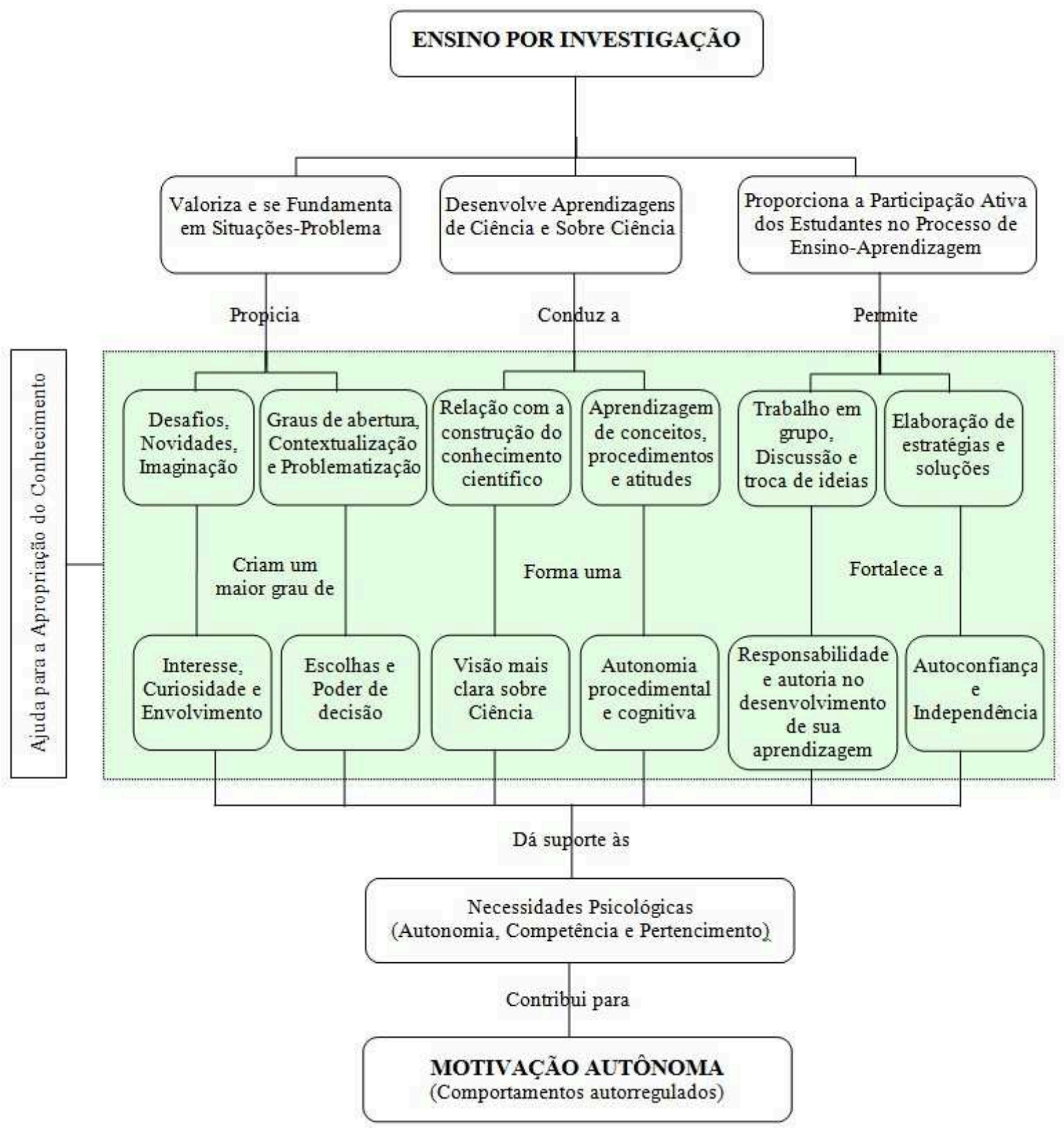

Fonte: Elaborada pelos autores. 
No plano superior (primeira linha) deste esquema (Figura 1) ressaltamos três características do ensino por investigação (importância das situações-problema; aprendizagens de ciência e sobre ciência; participação ativa dos estudantes), as quais consideramos serem as mais representativas e importantes desta perspectiva de ensinoaprendizagem. A partir destas características, traçamos um caminho para a formação de comportamentos de maior grau de autorregulação, evidenciando como alguns dos marcadores da motivação intrínseca (desafio; curiosidade; controle; imaginação; interesse; poder de escolha; contextualização e envolvimento nas tarefas; tomada de decisões; responsabilidade; autoria no processo de aprendizagem; autoconfiança; independência) podem ser trabalhados. Estes elementos, quando presentes durante a aula, auxiliam e promovem a satisfação das necessidades psicológicas dos estudantes (autonomia, competência e pertencimento), contribuindo para a maior autodeterminação dos mesmos (DECI et al., 1991; DECI; RYAN, 2000; GUIMARÃES, 2009; REEVE, 2006; RYAN; DECI, 2000a, 2000b).

No ensino por investigação, os níveis de desafio, curiosidade, novidade e o grau de abertura e contextualização das situações-problema são elementos que devem ser considerados durante a elaboração e proposição das atividades a serem tratadas em aula. Com isso, se desperta um maior interesse nos estudantes e, consequentemente, se alcança um maior envolvimento deles no processo de resolução das situações-problema. Para que haja um engajamento dos estudantes nas atividades propostas, motivado pelo interesse e pela curiosidade, é fundamental que as situações-problemas tenham relevância para os estudantes (ASSOR; KAPLAN; ROTH, 2002). O professor terá um papel determinante, pois, ele poderá ativar o interesse e a curiosidade do estudante (conhecendo a turma), mostrando-lhe de que valerá à pena se deter, envolvendo-se na atividade e percebendo que ali há realmente um problema a ser resolvido, ou seja, “[...] que há uma distância entre o que sabemos e o que queremos saber, e que essa distância merece o esforço de ser percorrida" (POZO; ANGÓN, 1998, p. 159). Sendo assim, no ensino por investigação prima-se por tarefas escolares que representem um maior sentido para os estudantes. Como afirma Pozo e Angón (1998, p. 160),

Para que se configurem verdadeiros problemas que obriguem o aluno a tomar decisões, planejar e recorrer à sua bagagem de conceitos e procedimentos adquiridos, é preciso que as tarefas sejam abertas, diferentes umas das outras, ou seja, imprevisíveis. Um problema é sempre uma situação de alguma forma surpreendente. 
Reiteramos aqui então, que o reconhecimento ou não de uma tarefa como problema dependerá essencialmente do estudante. Para propiciá-lo, é decisivo o tipo de atividades apresentadas a ele e a maneira com a qual estas são problematizadas, visando ressaltar sua contextualização e relevância. Como já afirmado anteriormente, as atividades didáticas com caráter investigativo podem ser desenvolvidas por diferentes formas, ou seja, mediante uma atividade de lápis e papel - resolução de problemas abertos; uma atividade com uso de experimento; uma atividade com uso de texto de divulgação científica; atividades teóricas, em que os alunos se envolvem em estudos de caso e deverão se posicionar frente a assuntos controversos; atividades com banco de dados, tendo como desafio a elaboração de uma argumentação baseada em evidências; atividades de simulação, explorando um fenômeno a partir de simulações em computador; entre outros (SÁ et al., 2007).

A possibilidade de diversificação de recursos didáticos presentes no ensino por investigação é muito importante para maximizar o envolvimento do estudante na tarefa e propiciar a ele diferentes tipos de escolhas e decisões a serem tomadas, para construir uma solução. Além disso, estes elementos se potencializam quando estas atividades são organizadas de forma a permitirem trabalhos em grupo (CLEMENT; TERRAZZAN, 2012). A capacidade para o trabalho em grupo configura-se, inicialmente, em um conhecimento a ser construído e aprimorado ao longo do tempo. Assim, para a construção de conhecimento em sala de aula são importantes atividades que proporcionam a interação social, particularmente, aquelas que permitem “[...] o diálogo, a cooperação e troca de informações mútuas, o confronto de pontos de vista divergentes e que implicam na divisão de tarefas onde cada um tem uma responsabilidade que, somadas, resultarão no alcance de um objetivo comum” (REGO, 1995, p. 110). É também sob este contexto que defendemos o ensino por investigação, pois, isso terá grande significado para o estabelecimento e fortalecimento de vínculos, satisfazendo a necessidade de pertencimento.

Numa perspectiva investigativa se procura a geração de um ambiente escolar em que a resolução dos problemas deve deixar de ser uma atividade repetitiva e com caráter de reprodução para ganhar status de situações-problema desafiadoras que ativem o pensamento e a criatividade dos estudantes. Esse aspecto se maximiza pela possibilidade de trabalhos realizados coletivamente, tendo como foco a construção de soluções para as situações-problema. Com isso se permite uma maior discussão conceitual bem como se possibilita que ocorra a aprendizagem e mobilização de 
POTENCIALIDADES DO ENSINO POR INVESTIGAÇÃO PARA PROMOÇÃO DA MOTIVAÇÃO...

procedimentos, tais como: recolha e seleção de informações; previsibilidade; formulação de hipóteses; elaboração de estratégias ou planos de ação; análise de informações e resultados; argumentação e comunicação; entre outros. Estes procedimentos são determinantes no desenvolvimento de competências por parte dos alunos, as quais terão sua importância e aplicabilidade também em outros contextos (CLEMENT, 2004).

O desenvolvimento de competências acaba sendo possível, pois, no ensino por investigação, assume-se que o estudante tem um papel ativo no processo de ensinoaprendizagem; sendo ele o autor de sua aprendizagem. Além disso, o que viabiliza o desenvolvimento de competências é a presença de conteúdos conceituais (conceitos, princípios e modelos), procedimentais (técnicas e estratégias de resolução adotadas; argumentação oral e escrita) e atitudinais (juízos, normas e valores) no desenvolvimento de atividades de caráter investigativo.

De maneira mais pragmática, a preocupação com os elementos motivacionais já deverá estar presente na elaboração das situações-problema, as quais são centrais em ações de ensino por investigação. Nesta etapa é importante que se dê atenção e se busque níveis ótimos de desafio, curiosidade, controle e imaginação/fantasia (GUIMARÃES, 2009; LEPPER; HODELL, 1989; PARKER; LEPPER, 1992; PINTRICH; SCHUNK, 2002). Entende-se aqui que o nível ótimo destes elementos não pode ser demarcado e fixado, ao contrário, ele irá depender da turma e do grau de escolarização (série). Em relação ao nível do desafio inerente à situação-problema, espera-se que seja buscado um equilíbrio de forma a não deixá-lo muito elevado (insuperável) e também não muito baixo, que gere desinteresse. Da mesma forma, devese agir em relação ao nível de curiosidade, buscando graus moderados de surpresa ou novidade e evitando que se criem discrepâncias muito acentuadas entre as crenças e conhecimentos anteriores dos estudantes. Em uma linguagem vigotskiana, deve-se buscar a formulação de situações-problema que proporcionem uma atuação dentro da zona de desenvolvimento proximal, pensando na distância entre os níveis real e potencial dos estudantes (OLIVEIRA, 1997; VYGOTSKY, 1984).

As situações-problema constituem atividades a ser desenvolvidas em sala de aula, um contexto no qual cabe ao professor o estabelecimento de controle do processo de ensino-aprendizagem. No caso do ensino por investigação, é fundamental que os estudantes possam ter um papel ativo, expressando e debatendo suas ideias, e isso deve ser levado em consideração no momento da elaboração das situações-problema, ou seja, 
deve-se formular problemas que permitam, em seu processo de solução, que os estudantes se envolvam e construam resoluções de sua autoria. Neste sentido, o elemento controle, da forma como defendem autores relacionados aos estudos da motivação (GUIMARÃES, 2009; LEPPER; HODELL; 1989; entre outros) pode ser satisfeito. Para Lepper e Hodell (1989), o senso de responsabilidade e a motivação intrínseca dos estudantes estão diretamente relacionados ao controle, isto é, ambientes escolares altamente controladores são inibidores destes aspectos afetivos.

O interesse dos estudantes pelas atividades escolares e, consequentemente, sua motivação intrínseca também mantém relação com a imaginação/fantasia nelas envolvido (GUIMARÃES, 2009; LEPPER; HODELL; 1989). Na elaboração das situações-problema é possível que se contemple este aspecto, buscando em algumas delas formulações voltadas a contextos fictícios, imaginários, de simulação ou mesmo com graus de ludicidade.

A proposição de promover regulações autônomas por intermédio do ensino por investigação, não obstante, prevê a participação ativa do professor no processo de aprendizagem. A ajuda para apropriação do conhecimento se caracteriza por ações didático-metodológicas do professor _ informações organizadas, sugestões, encaminhamentos, novas questões ou opções de escolha que combinadas com a atividade mental de construção do aluno permitem conduzir e encaminhar a aprendizagem para direção desejada (CUSTÓDIO et al., 2013). Ou seja, pensar em autonomia intelectual, e obter ganho na qualidade motivacional dos alunos, não é dar espaço para escolhas e tomadas de decisões e abandonar os alunos sozinhos na busca do saber científico, pois sem ajuda do professor "é altamente improvável que os alunos cheguem a aprender, e a aprender da maneira mais significativa possível, os conhecimentos necessários ao seu desenvolvimento pessoal e à sua capacidade de compreensão da realidade e de atuação nela, que a escola tem a responsabilidade social de transmitir" (ONRUBIA, 2009, 123).

Em uma visão mais ampla, a defesa pelo ensino por investigação se justifica, uma vez que, atividades centradas na resolução de problemas configuram uma "[...] situação didática na qual se propõe ao sujeito uma tarefa que ele não pode realizar sem efetuar uma aprendizagem precisa. E essa aprendizagem, que constitui o verdadeiro objetivo da [resolução da] situação-problema, se dá ao vencer o obstáculo na realização da tarefa" (Meirieu, 1997, p. 192). Portanto, atividades didáticas organizadas de acordo com o ensino por investigação podem ajudar no aprimoramento do desempenho necessário 
POTENCIALIDADES DO ENSINO POR INVESTIGAÇÃO PARA PROMOÇÃO DA MOTIVAÇÃO...

frente às exigências impostas pela sociedade atual, auxiliando no desenvolvimento da capacidade e da autonomia dos estudantes para enfrentarem situações-problema do diaa-dia.

\section{Considerações Finais}

Acreditamos que o aspecto investigativo, peculiar do ensino por investigação, tem potencial para despertar nos alunos interesse e maior engajamento no processo de construção de seus conhecimentos; culminando em maior qualidade motivacional (motivação autônoma). Motivações autônomas são desenvolvidas ou aprimoradas na medida em que os alunos percebem a sua responsabilidade e seu papel enquanto aprendizes. Este aspecto é bastante trabalhado em perspectivas de ensino por investigação, pois, visa-se a configuração de situações-problema que demandam participação ativa dos alunos na elaboração das soluções que, necessariamente, conduzem à aprendizagem de novos saberes.

Motivações autônomas relacionadas à aprendizagem são importantes para a construção do conhecimento escolar e, igualmente, poderão seguir guiando as aprendizagens necessárias na vida das pessoas. A escola não poderá adiantar as respostas de todos os desafios que cada pessoa enfrentará na vida, pois, por um lado, estes problemas não são previamente estabelecidos e, por outro, mesmo que pudessem ser previstos, seriam muitos e demasiadamente particularizados. Por essa razão, é fundamental que se dê uma maior atenção e importância para a formação da autonomia dos alunos. Pensamos que ações de ensino por investigação poderão contribuir para isso, em especial, quando desenvolvidas sob a perspectiva de oferecer ajudas apropriadas para atender tanto os elementos relativos à demanda cognitiva dos estudantes quanto àqueles inerentes à sua dimensão motivacional/afetiva.

O conjunto de aspectos coerentes presentes nos aportes teóricos do ensino por investigação e da teoria da autodeterminação fortalece nossa ideia de que há aí um aporte teórico frutífero para abordar a temática da motivação autônoma dos estudantes em processos educacionais, em especial, para o ensino e a aprendizagem das ciências da natureza. Destaca-se que há estudos empíricos na área de ensino de física (CLEMENT, 2013) em que os resultados alcançados indicam que ações didáticas orientadas pelo ensino por investigação atendem e satisfazem, em grande medida, as necessidades psicológicas de autonomia, competência e pertencimento. Isso fortalece nossa 
proposição teórica aqui apresentada, sintetizada pelo diagrama das características essenciais do ensino por investigação em busca da motivação autônoma (Figura 1).

É importante a realização de outros trabalhos de natureza teórico-metodológica para que se amplie a reflexão sobre o delineamento e o entendimento desta relação (teoricamente alinhavada) entre o ensino por investigação e a promoção da motivação autônoma de estudantes. Esses estudos poderão abranger as diferentes áreas da ciência da natureza, bem como, buscar suporte em outras perspectivas didático-pedagógicas, para avaliar como estas poderão contribuir com processos de ensino-aprendizagem preocupados com a autodeterminação dos estudantes, na construção de seus conhecimentos em sala de aula.

\section{Referências}

ABD-EL-KHALICK, F. et al. Inquiry in Science Education: international perspectives. Science Education, v. 88, n. 3, p. 397-419, 2004.

ALVES FILHO, J. P. Atividades experimentais: do método a prática construtiva. Florianópolis: UFSC, 2000. (Tese de Doutorado).

ANDRADE, G. T. B. Percursos Históricos de Ensinar Ciências Através de Atividades Investigativas. Revista Ensaio, v. 13, n. 1, p. 121-138, 2011.

ASSOR, A.; KAPLAN, H.; ROHT, G. Choice is Good, but Relevance is Excellent: autonomy-enhancing and suppressing teacher behaviours predicting students' engagement in schoolwork. British Journal of Education Psychology, v. 72, p. 261-278, 2002.

AZEVEDO, M. C. P. S. Ensino por Investigação: problematizando as atividades em sala de Aula. In: CARVALHO, A. M. P. de (org.). Ensino de Ciências: unindo a pesquisa e a prática. $2^{\mathrm{a}}$ reimp. (1 ${ }^{\mathrm{a}}$ ed. 2004), São Paulo: Cengage Learning, 2009. p. 19-33.

BALLENILLA, F. Enseñar Investigando: cómo formar professores desde la práctica? $3^{\text {a }}$. ed. Sevilla: Díada, 1999. (Serie Practica, n.12. Coleção Investigación y Enseñanza).

BARAM-TSABARI, A.; YARDEN, A. Characterizing children's spontaneous interests in science and technology. International Journal of Science Education, v. 27, n. 7, p. 803-826, 2005.

BARROW, L. H. A Brief History of Inquiry: From Dewey to Standards. Journal of Science Teacher Education, v. 17, n. 3, p. 265-278, 2006.

BORGES, A. T. Novos rumos para o laboratório escolar de ciências. Caderno Brasileiro de Ensino de Física, v. 19, n. 3, p. 291-313, 2002. 
BORUCHOVITCH E.; BZUNECK, J. A. Motivação para Aprender no Brasil: estado da arte e caminhos futuros. In: BORUCHOVITCH, E.; BZUNECK, J. A.; GUIMARÃES, S. E. R. (Orgs.). Motivação para Aprender: aplicações no contexto educativo. Petrópolis-RJ: Vozes, 2010. p. 231-354.

BORUCHOVITCH, E. Dificuldades de aprendizagem, problemas motivacionais e estratégias de aprendizagem. In: SISTO, F. F et al. (Orgs.). Dificuldades de aprendizagem no contexto psicopedagógico. $5^{\mathrm{a}}$ ed. Petrópolis/RJ: Vozes, 2007. p. 40-59.

BRASIL. Ministério da Educação, Secretaria de Educação Básica. Orientações Curriculares para o Ensino Médio: Ciências da natureza, matemática e suas tecnologias. Brasília: Ministério da Educação, 2006. (Orientações curriculares para o ensino médio, volume 2).

- Ministério da Educação, Secretaria de Educação Média e Tecnológica. Parâmetros Curriculares Nacionais: ensino médio. Brasília: Ministério da Educação, 2000.

Secretaria de Educação Média e Tecnológica. PCN+ Ensino Médio: orientações educacionais complementares aos Parâmetros Curriculares Nacionais. Ciências da Natureza, Matemática e suas Tecnologias. Brasília: MEC, SEMTEC, 2002.

BZUNECK, J. A. A motivação do aluno: aspectos introdutórios. In: BORUCHOVITCH, E.; BZUNECK, J. A. (Orgs.). A Motivação do Aluno: contribuições da psicologia contemporânea. $4^{\text {a }}$ Ed., Petrópolis/RJ: Vozes, 2009. p. 9-36.

BZUNECK, J. A.; GUIMARÃES, S. E. R.. A promoção da autonomia como estratégia motivacional na escola: uma análise teórica e empírica. In: BORUCHOVITCH, E.; BZUNECK, J. A.; GUIMARÃES, S. E. R. (Orgs.). Motivação para Aprender: aplicações no contexto educativo. Petrópolis/RJ: Vozes, 2010. p. 43-70.

CAÑAL, P. et al. Investigar en La Escola: elementos para uma enseñanza alternativa. $1^{\text {a }}$. ed. Sevilla/ES: DÍADA, 1997. 342 p. (Série Fundamentos, n. 7. Colección Investigación y Enseñanza).

CARVALHO, A. M. P. O Ensino de ciências e a proposição de sequências de ensino investigativas. CARVALHO, A. M. P. (Org.). Ensino de Ciências por Investigação: condições para implementação em sala de aula. São Paulo: Cengage Learning, 2013. p. $1-20$.

CHINN, C. A.; MALHOTRA, B. A. Epistemologically authentic inquiry schools: a theorical framework for evaluating inquiry tasks. Science Education, v. 86, n. 2, p. 175$218,2002$.

CLEMENT, L. Resolução de Problemas e o Ensino de Procedimentos e Atitudes em Aulas de Física. Santa Maria/RS: UFSM, 2004. (Dissertação de Mestrado).

CLEMENT, L. Autodeterminação e Ensino por Investigação: construindo elementos para promoção da autonomia em aulas de física. Florianópolis/SC: PPGECT-UFSC, 2013. (Tese de Doutorado). 
CLEMENT, L.; TERRAZZAN, E. A. Atividades Didáticas de Resolução de Problemas e o Ensino de Conteúdos Procedimentais. Revista Electrónica de Investigación en Educación en Ciências, v. 6, n. 1, p. 87-101, 2011.

.Resolução de Problemas de Lápis e Papel numa Abordagem Investigativa. Experiências em Ensino de Ciências, v. 7, n. 2, p. 98-116, 2012.

CUSTÓDIO, J. F.et al. Práticas didáticas construtivistas: Critérios de análise e caracterização Tecné, Episteme y Didaxis (TED), v. 33, p. 11-35, 2013.

DEBOER, G. E. Historical Perspectives on Inquiry Teaching in Schools. In: FLICK, L.B.; LEDERMAN, N. G. (Editores). Scientific Inquiry and Nature of Science: implications for teaching, learning and teacher education. Norwell: Kluwer Academic Publishen, 2006. p. 17-35.

DECI, E. L., et al. Motivation in education: the self-determination perspective. Educational Psychologist, v. 26, n. 3/4, p. 325-346, 1991.

DECI, E. L.; RYAN, R. M. Intrinsic motivation and self-determination in human behavior. New York. Plenum Press, 1985.

. A Motivational Approach to Self: Integration in Personality. In: DIENSTBIER, R. (ed.). Nebraska Symposium on Motivation: Perspectives on Motivation. Lincoln: university of Nebraska Press, v. 38, p. 237-288, 1990.

.The "What" and "Why" of Goal Pursuits: human needs and the SelfDetermination of Behavior. Psychological Inquiry, v. 11, n. 4, p. 227-268, 2000.

FERNANDES, F.; LUFT, C. P.; MARQUES GUIMARÃES, F. Dicionário Brasileiro Globo, 43ª ed., São Paulo: Globo, 1996.

FLOR, J. I. Recursos para la investigación en el aula. 2a ed., Sevilla/ES: DÍADA, 1996. 82 p. (Série Practica, n. 8. Colección Investigación y Enseñanza).

GARCÍA, E. J.; GARCÍA, F. F. Aprender investigando: una propuesta metodológica basada en la investigación. 7ª ed. Sevilla/ES: DÍADA, 2000. 93 p. (Série Practica, n. 2. Colección Investigación y Enseñanza).

GIL PÉREZ, D. et al. Questionando a didática de resolução de problemas: elaboração de um modelo alternativo. Caderno Catarinense de Ensino de Física, v. 9, n. 1, p. 0719, 1992.

GUIMARÃES, S. E. R. Motivação intrínseca, extrínseca e o uso de recompensas em sala de aula. In: BORUCHOVITCH, E.; BZUNECK, J. A. (Orgs.). A Motivação do Aluno: contribuições da psicologia contemporânea. 4ª Ed., Petrópolis/RJ: Vozes, 2009. p. 37-57. 
GUIMARÃES, S. E. R.; BORUCHOVITCH, E. O Estilo Motivacional do Professor e a Motivação Intrínseca dos Estudantes: uma perspectiva da teoria da autodeterminação. Psicologia: Reflexão e Crítica, v. 17, n. 2, p.143-150, 2004.

KOH, J. H. L.; FRICK, T. W. Implementing Autonomy Support: Insights from a Montessori Classroom. International Journal of Education, v. 2, n. 2, p. 1-15, 2010.

KRAPP, A.; PRENZEL, M. Research on interest in science: theories, methods, and findings. International Journal of Science Education, v. 33, n. 1, p. 27-50, 2011.

LEPPER, M. R.; HODELL, M. Intrinsic motivation in the classroom. Research on motivation in education, v. 3, p. 73-105, 1989.

MEIRIEU, P. Aprender... Sim, mas como? Porto Alegre: Artmed, 1997.

MENEGAT, T. M. C.; CLEMENT, L.; TERRAZZAN, E. A. Textos de divulgação científica em aulas de física: uma abordagem investigativa. In: VI ENCONTRO NACIONAL DE PESQUISA EM ENSINO DE CIÊNCIAS. Anais do VI ENPEC, Florianópolis: ABRAPEC, 2007.

MUNFORD, D.; LIMA, M. E. C. C. Ensinar ciências por investigação: em quê estamos de acordo?. Revista Ensaio, v. 9, n. 1, 2007.

NATIONAL RESEARCH COUNCIL (NRC). Inquiry and the National Science Education Standards: a guide for teaching and learning. $10^{\text {th }}$ Printing, Washington, DC: National Academy Press, 2008. 202 p. Press, 1996.

. National Science Education Standards. Washington, DC: National Academy

NEVES, E. R. C.; BORUCHOVITCH, E. Escala de Avaliação para Aprender de Alunos do Ensino Fundamental (EMA). Psicologia: Reflexão e Crítica, v. 20, n. 3, p. 406-413, 2006.

OLIVEIRA, M. K. Vygotsky: aprendizado e desenvolvimento - um processo sóciohistórico. São Paulo: Scipione, 1997. (Série: Pensamento e Ação no magistério).

ONRUBIA, J. Ensinar: criar zonas de desenvolvimento proximal e nelas intervir. In: COLL, C. et al. (Orgs.). O Construtivismo na sala de aula. São Paulo: Ática, 2009. p. 123-152.

PARKER, L. E.; LEPPER, M. R. Effects of fantasy contexts on children's learning and motivation: making learning more fun. Journal of Personality and Social Psychology, v. 62, p. 625-633, 1992.

PEDUZZI, L. O. Q. Sobre a resolução de problemas no ensino da física. In: Caderno Catarinense de Ensino de Física, v. 14 n. 3, p. 229-253, 1997.

PINTRICH, P. R.; SCHUNK, D. H. Motivation in education: theory, research, and applications. 2a. ed. Upper Saddle River, NJ: Merrill, 2002. 460 p. 
POZO, J. I.; ANGÓN, Y. P. A solução de problemas como conteúdo procedimental da educação básica. In: POZO, J. I. (Org.). A solução de Problemas: aprender a resolver, resolver para aprender. Porto Alegre: Artes Médicas, 1998. p. 139-165.

REEVE, J.; JANG, H. What teachers say and do to support students' autonomy during a learning activity. Journal of educational Psychology, n. 98, p. 209-218, 2006.

REGO, T. C. Vygotsky: uma perspectiva histórico-cultural da educação. Petrópolis: Vozes, 1995.

RICARDO, E. C. Problematização e Contextualização no Ensino de Física. In: CARVAlHO, A. M. P., et al. Ensino de Física. São Paulo: Cengage Learning, 2010. p. 29-51. (Coleção Idéias em Ação).

ROTH, G. et al. Autonomous Motivation for Teaching: How Self-Determined Teaching May Lead to Self-Determined Learning. Journal of education Psychology, v. 99, n. 4, p. 761-774, 2007.

RUFINI, S. E.; BZUNECK, J. A.; OLIVEIRA, K. L. A Qualidade da Motivação em Estudantes do Ensino Fundamental. Paidéia, v. 22, n. 51, p. 53-62, 2012.

RYAN, R. M. Psychological needs and the facilitation of integrative processes. Journal of Personality, v. 63, p. 397-427, 1995.

RYAN, R. M.; DECI, E. L. Intrinsic and extrinsic motivations: Classic definitions and new directions. Contemporary Educational Psychology, v. 25 n. 1, p.54-67, 2000a.

.Selfdetermination theory and the facilitation of intrinsic motivation, social development, and well-being. American Psychologist, v. 55 n. 1, p. 68-78, 2000 b.

Self-Regulation and the Problem of Human Autonomy: does psychology need choice, self-determination, and will? Journal of Personality, v. 74, n. 6, p. 1558-1586, 2006.

RYAN, R. M.; STILLER, J. The social contexts of internalization: parent and teacher influences on autonomy, motivation and learning. In: PINTRICH, P. R.; MAEHR, M. L. (Eds.). Advances in motivation and achievement, v. 7 (goals and self-regulatory processes), Greenwich, CT: JAI Press, 1991. p. 115-149.

RYAN, R. M.; STILLER, J.; LYNCH, J. H. Representations of relationships to teachers, parents, and friends as predictors of academic motivation and self-esteem. Journal of Early Adolescence, v. 14, p. 226-249, 1994.

SÁ, E. F. et al. As características das atividades investigativas segundo tutores e coordenadores de um curso especialização em ensino de ciências. In: VI ENCONTRO NACIONAL DE PESQUISA EM ENSINO DE CIÊNCIAS. Anais do VI ENPEC, Florianópolis: ABRAPEC, 2007. 
SEGURA, D. de J.; MOLINA, A.; PEDREROS, R. I. Actividades de investigación en la clase de ciencias. 2a . ed. Sevilla: Díada, 1997. (Serie Practica, n.14. Coleção Investigación y Enseñanza).

TSAI, Y. et al. What Makes Lessons Interesting? The Role of Situational and Individual Factores in Three School Subjects. Journal of Educational Psychology, v. 100, n. 2, p. 460-472, 2008.

VYGOTSKY, L. S. A Formação Social da Mente. São Paulo: Martins fontes, 1984.

WHITE, R. W. Motivation reconsidered: the concept of competence. Psychological Review, v. 66, p. 297-333, 1959.

LUIZ CLEMENT. Possui graduação em Licenciatura em Física pela Universidade Federal de Santa Maria (2002), mestrado em Educação pela Universidade Federal de Santa Maria (2004) e doutorado em Educação Científica e Tecnológica pela Universidade Federal de Santa Catarina (2013). É Professor Adjunto do Departamento de Física - Centro de Ciências Tecnológicas - da Universidade do Estado de Santa Catarina (UDESC). Tem experiência na área de Educação, com ênfase em Ensino de Física, atuando principalmente nos seguintes temas: Cognição, Motivação, Ensino por Investigação, Resolução de Problemas, Formação Inicial de Professores e Didática das Ciências.

JOSÉ FRANCISCO CUSTÓDIO. Possui graduação em Licenciatura em Física pela Universidade Federal de Santa Catarina (1999), Mestrado em Educação pela Universidade Federal de Santa Catarina (2002), Doutorado em Educação Cientifica e Tecnológica pela Universidade Federal de Santa Catarina (2007). É ex-professor da Universidade do Estado de Santa Catarina. Atualmente é Professor Adjunto III da Universidade Federal de Santa Catarina. Também é docente permanente do Programa de Pós-Graduação em Educação Cientifica e Tecnológica (PPGECT) da UFSC. Tem experiência na área de Educação, com ênfase em Tópicos Específicos de Educação. Atuando principalmente nos seguintes temas: Explicações, Modelos, Cognição, Motivação, Sentimento de Entendimento e Sentimento de Realidade.

JOSÉ DE PINHO ALVES FILHO. É Bacharel em Física pela Universidade Federal do Rio Grande do Sul (1969), Mestre em Educação pela Universidade Federal de Santa Catarina (1990), Doutor em Educação: Ensino de Ciências Naturais pela Universidade Federal de Santa Catarina (1998) e pós-doutoramento na Universidade de Aveireo/Portugal (2009). É professor do Departamento de Física da Universidade Federal de Santa Catarina desde 1976 e atualmente é professor Associado II. Também é docente efetivo do Programa de Pós-Graduação em Educação Cientifica e Tecnológica (PPGECT) da UFSC. Tem experiência na área de Educação/Física, com ênfase em Métodos e Técnicas de Ensino, atuando principalmente nos seguintes temas: Atividades Experimentais, Alfabetização Cientifica e Técnica (interdisciplinaridade - Ilhas de Racionalidade) e Didática das Ciências.

Recebido: 14 de julho de 2014

Aceito: 11 de novembro de 2014 